rates in man using $-\mathrm{H},{ }^{\wedge} \mathrm{O}$-labelled water; comparisons between calorimeter and isotope values. In: van Es AJH, ed. Human energy metabolism. Wageningen: Euro-Nut. 1985:126-8.

6 Prentice AM. Coward W'A, Davies HL, et al. Lnexpectedly low levels of energy expenditure in healthy women. Lancet 1985;1:1419-22.

Courd W. Prentice A 11 . Isotope method for the measurement of carbon dioxide production in man 1 7 C lin Vur 1985:41:659-61.

8 Paul AA. Southgate DAT, eds. McCance and Widdowson's the compostzon of foods. London H.MSO, 1978 .

Metropolitan Life Insurance Company, New York. Mortality among overweight men and women Statistical Bulletin 1960; $\mathrm{No}_{0}+1$

10 Garrow JS. Treat obesty seriously: a clintial manual. London: Churchill Livingstone, 1981

11 Zed CA. The factors affecting energy balance in ohese and non-ohese people. Cambridge: Lniversity of Cambridge, 1982. PhD thesis.

12 Ravussin E. Burnand B, Schutz Y, Jequier E. Twentw-four-hour energy expenditure and resting

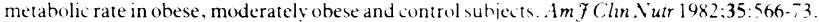

13 Blaza S. (Garrow JS. Thermogenic response to temperature, exercise and food stimuli in lean and obese women, studied by 24 h direct calorimetry. Br 7 . Nutr 1983:49:171-80.
14 Schoticld W.N. Schofield C. James W'P1. Basal metabolic rate. Hum Nutr C.lm Nutr 1985:39C suppl $1: 1-96$

15 Schutz Y, Bessard T, Jequier E. Diet-induced thermogenesis measured over a whole dav in ohese and non-obese women. Am f Clin. Nutr 1984;40:542-52

16 Edholm OG. Energy balance in man. 7 Hum 1 utur 1977:31:413-32.

17 Griffiths M. Pavne PR. Energy expenditure in small children of obese and non-obese parents. Vurure $19760200698-700$

8 Roval College of Phvsicians. Obesitv. 7 R Coll Phvsicians Lond 1983:17:5-65.

19 Garrow JS. Blaza SE, Warwick PM, A shwell MA. Predisposition to obesity. Lancet 1980;i: $1103-4$ 20 Halliday D, Hesp R, Stalley SF, Warwick PM, Altman DG, Garrow JS. Resting metabolic rate, surface area and body composition in obese women on a reducing diet. Int f Obes 1979;3: 1-6.

21 James WPT, Davies HI, Bailes J, Dauncey MJ. Elevated metabolic rates in obesity. Iance 1978;i:1122-5

22 Garrow JS. Webster J. Are pre-obese people energy thrifty? Lancet 1985;i:670-1

Accepted 21 Februan 1980

\title{
Reasons for poor prognosis in British patients with cutaneous malignant melanoma
}

\author{
VALERIE R DOHERTY， RONA M MACKIE
}

\begin{abstract}
One hundred and twenty five patients presenting in the west of Scotland with primary cutaneous malignant melanoma answered a detailed questionnaire to establish whether there was any evidence of inappropriate delay in receiving surgical treatment for a new or changing pigmented lesion. The survey was carried out because of the relatively high proportion of patients in Scotland with melanoma presenting with primary lesions categorised as "thick, poor prognosis" and the poor five year survival figures as compared with many other countries.

Of the 125 patients questioned, only $20(16 \%)$ had received appropriate surgical treatment within three months of becoming aware of a suspicious cutaneous pigmented lesion; $63(50 \%)$ had received surgical treatment three to 12 months after first noticing such a change, and in 42 cases (34\%) this interval was over one year. In 102 of 105 patients in whom the interval exceeded three months the patient alone was responsible for the delay; in only three cases was the family doctor partially at fault. No evidence of delay by the hospital service was identified. Because of these findings a public education campaign was launched in the west of Scotland in June 1985 with the aim of improving recognition of early malignant melanoma. In the next six months the proportion of patients in the west of Scotland with primary melanomas categorised as "thin, good prognosis" had risen from $38 \%$ to $62 \%$, and the proportion with tumours categorised as "thick, poor prognosis" had fallen from $34 \%$ to $15 \%$.
\end{abstract}

\section{Introduction}

In a recent extensive survey of incidence and survival statistics in patients with cutaneous malignant melanoma from centres in all parts of the world the overall five year survival rate for over 8000 patients presenting with stage I malignant melanoma (mainly

Department of Dermatology, University of Glasgow

VALERIE R DOHERTY, MB, MRCP, registrar for the Scottish Melanoma Group RONA M MACKIE, FRCP, FRCPATH, professor

Correspondence to: Professor R M Mackic, Department of Dermatology, Glasgow University, Glasgow G12 8QQ. during $1970-5$ ) was $79 \%-83 \%$ for women, $72 \%$ for men. This high figure contrasts with the $62 \%$ overall $(65 \%$ for men, $53 \%$ for women) reported by the Scottish Melanoma Group for Scottish patients presenting in 1979. Figures from England and Wales for the same period show an even poorer five year survival ( $58 \%$ for women, $44 \%$ for men).

Analysis of data from individual centres in the comprehensive survey showed that the highest five year survival rates occurred in centres where a large proportion of patients presented with primary melanomas categorised as "thin, good prognosis." It is well established that the most important prognostic factor for the individual patient with primary or stage I cutaneous malignant melanoma is the Breslow tumour thickness of the primary lesion." This is calculated microscopically from the granular layer of the overlying epidermis to the deepest underlying melanoma cell. Most centres now categorise patients with primary cutaneous malignant melanoma as having a good, intermediate, or poor prognosis based on tumour thicknesses of under $1.5 \mathrm{~mm}$ (thin lesions), $1.5-3.5 \mathrm{~mm}$ (intermediate lesions), and over $3.5 \mathrm{~mm}$ (thick lesions) respectively.

The prognostic value of tumour thickness is proved by correlating it with five vear survival. Thus in a series from Duke University of 2470 patients with melanoma the five year survival rate was $81 \%$, and $58 \%$ of patients from that centre had primary tumours less than $1.5 \mathrm{~mm}$ thick. Similarly, in 3025 patients reported from Sydney the five year survival rate was $79 \%$, and $55 \%$ of those patients had tumours less than $1.5 \mathrm{~mm}$ thick. By contrast, in the Scottish series of 1318 patients only $39 \%$ had primary tumours less than $1.5 \mathrm{~mm}$ thick at the time of surgical excision. ${ }^{2} \mathrm{No}$ comparable data are available for Breslow thickness measurements in a large series of melanomas from England and Wales.

These figures suggest that the poorer five year survival for British patients with primary malignant melanoma may be due at least in part to the smaller proportion presenting with thin tumours in the good prognosis category. It has been suggested that the "biological behaviour" of melanoma may differ throughout the world, possibly owing to the systemic effects of varying intensity of sunlight, and this has been advanced to explain the better survival figures in Sydney. Nevertheless, the fact that in Sweden (which is on a very similar latitude to Scotland) the five year survival figure is $80 \%$, and $50 \%$ of Swedish patients present with tumours $1.5 \mathrm{~mm}$ or less in thickness," suggests that geographical variations alone are unlikely to be the explanation for the poor Scottish figures.

We have therefore carried out a study designed to establish whether the relatively low proportion of patients presenting in 
Scotland with thin primary melanomas is related to delay in receiving appropriate surgical treatment and if so whether this delay is due to the hospital service, the family doctor, or the patient. It was planned that the results of this survey would be used to establish whether there was a need for an educational campaign aimed at improving recognition of early melanoma and the appropriate target audience for such a campaign.

\section{Patients and methods}

We studied 125 patients (88 women, 37 men) aged 19-82. All first presented to the Western Infirmary, Glasgow, with primary cutaneous malignant melanoma between 1981 and 1985. All were questioned in detail by one of us. They were asked to state as accurately as possible (1) the date when they first became aware of a new pigmented lesion or of growth or change in a pre-existing benign pigmented naevus. They were then asked to state (2) the date on which they first sought advice from their family doctor. The date on which the family doctor arranged specialist referral (3), the date on which the patient was actually seen at a specialist referral clinic (4), and the date on which surgical excision of the primary tumour was carried out (5) were all verified from hospital records. Thus the interval between date points (1) and (2) was an indication of delay for which the patient alone was responsible, the interval between (2) and (3) gave an indication of delay for which the family doctor was responsible, the interval between (3) and (4) gave an indication of hospital delay due to waiting lists for outpatient appointments, and the interval between (4) and (5) indicated delay due to waiting lists for surgical sessions.

The only element of selection in our study was the patient's willingness to answer the questionnaire, and only eight patients declined. The age distribution, the $2: 1$ female to male distribution, and the relative proportions of the different pathological subtypes were all very similar to those seen in the 1318 patients with melanoma registered by the Scottish Melanoma Group. ${ }^{2}$ That group comprises virtually all new patients with melanoma who presented in Scotland between 1979 and 1983. We are therefore reasonably confident that the 125 patients included in our study were representative of all Scottish patients with melanoma. Moreover, the Scottish Melanoma Group has found over the past seven years that patients from Glasgow and the west of Scotland comprised just over half of the total and also that each year the age distribution, sex distribution, clinicopathological subtype, and Breslow thickness were very similar and showed no variation between the Scottish regions.

Pigmented lesion clinics-A weekly pigmented lesion clinic is held at the hospital and functions as a rapid referral clinic with no waiting list, so that all patients referred are seen within a week. Local family doctors use the clinic sensibly, referring relatively non-urgent cases by letter and urgent cases by telephone. In addition to this clinic, consultants likely to see malignant melanoma in other hospitals in the west of Scotland also regard melanoma as an emergency and arrange for surgery within one week of first seeing the patient, if not sooner.

\section{Results}

Of the 125 patients questioned, only $20(16 \%)$ had a total time interval of less than three months between date points (1) and (5) - that is, between first noticing a new or changing pigmented lesion and undergoing surgical excision. In 63 patients $(50 \%)$ this interval was between three and 12 months, and in 42 patients ( $34 \%$ ) it was longer than one year (see table I).

Statistical analysis was by $\chi^{2}$ test and the Bonferroni technique for multiple comparisons where appropriate.

Points at which delay occurred-In none of the 125 patients studied was there a delay of more than three weeks between the date of referral by the family doctor and surgical excision, and in many cases this interval was less than a week. This may have been due in part to the weekly pigmented lesion clinic, at which most of the patients with suspected malignant melanomas were seen. In only three cases $(2 \cdot 4 \%)$ was there any evidence of delay on the part of the family doctor. The delays in these cases were six weeks, eight weeks, and 16 weeks respectively. All three patients, however, had been slow in first contacting their doctor, waiting more than three months after first becoming aware of new or changing lesions. Thus of 105 patients $(84 \%)$ with longer than three months between first noticing a suspicious pigmented lesion and its surgical removal, delay in 102 was attributable exclusively to the patient.

Age of patients-The mean age at presentation of those patients who delayed less than three months was 47 years (range 19-71), the mean age of those who delayed three to 12 months was 48 years (range 22-79), and the mean age in those who delayed over one year was 52 years (range 29-82).
These differences were not significant (Bonferroni technique for multiple comparisons) and did not suggest a specific age group such as those over 65 requiring an educational programme more than any other.

Sex of patient and site of melanoma-There was no difference in length of delay between men and women. Nor was any significant difference in delay detected when "socially visible" sites (forearms, hands, neck, face, and (in women) lower legs) were compared with habitually covered sites ( $\chi^{2}$ test; tables I, II).

TABLE I-Sex distribution of patients related to delay interial

\begin{tabular}{lrrrr}
\hline & \multicolumn{3}{c}{ Delay period (months } & \\
\cline { 2 - 4 } & $<3$ & $3-12$ & $>12$ & Total \\
\hline No of men & 6 & 21 & 10 & 37 \\
No of women & 14 & 42 & 32 & 88 \\
\hline Total & 20 & 63 & 42 & 125 \\
\hline
\end{tabular}

Differences in delay between men and women not significant $\left(\chi^{2}\right.$ test).

TABLE II-Site of melanoma related to delay period

\begin{tabular}{lccccc}
\hline & \multicolumn{3}{c}{ Delay period (months) } \\
\cline { 2 - 4 } & $<3$ & $3-12$ & $>12$ & Total \\
\hline Usually covered & 6 & 30 & 22 & 58 \\
"Socially visible" & 14 & 33 & 20 & 67 \\
\hline All sites & 20 & 63 & 42 & 125 \\
\hline Differences in delay between groups not significant $\chi^{2}$ test).
\end{tabular}

Reasons for delay-Of the 105 patients in whom the delay was longer than three months, $99(94 \%)$ gave as the reason their lack of knowledge of the possible serious consequences of a new or growing cutaneous pigmented lesion. Four patients had delayed because of difficult family circumstances such as chronic illness in another family member, and two patients delayed because of fear of the extent of possible surgical treatment.

\section{Discussion}

This study shows clearly that in Scottish patients with melanoma the high proportion presenting with thick primary tumours carrying a poor prognosis may be partly due to lack of knowledge of the features of early malignant melanoma resulting in a disturbingly long delay before seeking medical advice.

In a study of 106 patients with melanoma carried out in California by Temoshok et al delay was analysed according to anatomical site of lesions." A "long delay" was defined as six months. The mean delay was 2.9 months for lesions on the head and neck, 3.6 months for limb lesions, 3.3 months for chest and abdominal lesions, and 6.0 months for lesions on the upper and lower back. These variations in delay were interpreted as being due to a lack of easy visibility of the lesions rather than to a lack of knowledge of features of early malignant melanoma. In our study the mean delay for all body sites was 15 months and there were no variations in delay clearly associated with sites of lesions, suggesting that lack of knowledge rather than lack of visibility was more important. This impression was confirmed verbally by patients themselves. We can trace no other published reports on the problem of delay before treatment in patients with melanoma.

This project was carried out to see whether a melanoma education campaign might be likely to improve the prognosis of patients with malignant melanoma in Scotland. The findings showed that such a campaign was not only justified but needed and clearly indicated that it was the patient rather than the family doctor who urgently required information. 


\section{ACTION TAKEN AS A RESULT OF STUDY}

On the basis of our findings a pigmented lesion education campaign aimed at the public was established in the west of Scotland. With the help of the Health Education Department of the Greater Glasgow Health Board, posters and leaflets were prepared illustrating the features of early malignant melanoma and encouraging patients who recognised such lesions on their own skin to consult their family doctor immediately. These materials were distributed to doctors' surgeries, infant welfare clinics, public libraries, and other public places during a week of intense publicity in early June 1985. Press releases resulted in publicity in six national newspapers, four radio programmes, and five television programmes. Before the campaign all 650 family doctors in Glasgow had been alerted to prepare them for a likely increase in patients seeking advice about pigmented lesions. They had all been issued with a booklet reminding them of the features of malignant melanoma and its differential diagnosis and an invitation to attend one of five meetings describing the campaign held throughout the city. Additional printed material was available on request, and a videotape prepared specifically for the campaign was made available to be shown in surgeries, health centres, and postgraduate centres. A further series of meetings and distribution of booklets were arranged for general practitioners in the adjacent health board areas of Lanarkshire, Ayrshire and Arran, and Forth Valley.

Public response to the campaign was rapidly evident, with a sharp increase in patients referred to the pigmented lesion clinic within two weeks of the start of the campaign. Preliminary analysis of these patients to establish the most effective form of publicity in prompting patients to consult their doctor suggested that television was best. A detailed analysis of referral patterns for both malignant melanoma and benign pigmented skin lesions before and after the campaign in the west of Scotland is currently in progress. At present it is planned that the public educational aspect of this exercise will be continued with a brief yearly reminder campaign in the late spring or early summer.

Though changes in five year survival for cutaneous malignant melanoma will be the ultimate measure of the campaign's success, an initial indicator of its effect is an increase in the proportion of patients with primary melanomas in the under $1.5 \mathrm{~mm}$ category and a decrease in those thicker than $3.5 \mathrm{~mm}$. Tables III and IV show these proportions during 1979-83 inclusive for the whole of Scotland and for the west of Scotland respectively. A stable distribution of melanomas among the three categories was evident over this period both locally and nationally. In the period July to November 1985, however, a pronounced change in distribution of melanomas among these three categories was seen, $62 \%$ of patients

TABLE III-Patients in Scotland with primary melanomas in thin, intermediate, and thick categories (1979-83). Figures are numbers of patients (percentages in parentheses)

\begin{tabular}{|c|c|c|c|c|}
\hline \multirow[b]{2}{*}{ Year } & \multicolumn{3}{|c|}{ Thickness (mm) } & \multirow[b]{2}{*}{ Total } \\
\hline & $<1.5$ & $1 \cdot 5-3 \cdot 49$ & $\geqslant 3 \cdot 5$ & \\
\hline 1979 & $92(37)$ & $78 \cdot 31$ & $8132:$ & 251 \\
\hline 1980 & 10544 & $62(26$ & 6929 & 236 \\
\hline 1981 & 8136 & $66(29)$ & 7935 & 226 \\
\hline 1982 & $99(39)$ & 7128 & $82(33)$ & 252 \\
\hline 1983 & 11740 & 9633 & $81(28)$ & 294 \\
\hline Total & $494(39)$ & $373(30)$ & $392(31)$ & 1259 \\
\hline Five year survival for 1979 cohort & $91 \%$ & $67 \%$ & $38 \%$ & \\
\hline
\end{tabular}

in the west of Scotland with melanomas presenting with primary lesions of $1.5 \mathrm{~mm}$ or less in thickness (38\% before the campaign) and only $15 \%$ of patients with lesions thicker than $3.5 \mathrm{~mm}(34 \%$ before the campaign). Five year survival figures for patients in Scotland with tumours in these categories are $91 \%$ and $38 \%$ respectively. This is very encouraging and suggests that five year survival from melanoma should improve as a result of educational efforts aimed at patients. Unfortunately, there is not at present any area in the United Kingdom outside Scotland with as complete registration and as complete data on Breslow thickness which might have provided a control group. Even had such a group existed, the fact that certain aspects of the campaign were publicised on national television programmes and in newspapers would have confounded interpretation of the results.

\begin{tabular}{|c|c|c|c|c|}
\hline \multirow[b]{2}{*}{ Year } & \multicolumn{3}{|c|}{ Thickness $\mathrm{mm}$} & \multirow[b]{2}{*}{ Total } \\
\hline & $<1.5$ & $1 \cdot 5-3 \cdot 49$ & $23 \cdot 5$ & \\
\hline 1979 & $50 \quad 40$ & $34: 27$ & t) 32 & 124 \\
\hline 1980 & $52: 39$ & $34: 26$ & $+6,35$ & 132 \\
\hline 1981 & +335 & $35 \quad 28$ & 45,37 & 123 \\
\hline 1982 & 4638 & 29.24 & $+5,38$ & 120 \\
\hline 1983 & 60.39 & $45 \quad 29$ & 49.32 & 154 \\
\hline Total & $251 \cdot 38$ & 177,27 & 22534 & 653 \\
\hline
\end{tabular}

An important additional advantage of this approach is a reduction in the need for admission to hospital and thus in hospital costs, as a high proportion of patients with thin melanomas require only local excision, which can often be performed on an outpatient basis. The possibility of carrying out similar educational activities in other parts of Britain is being considered.

VRD is supported by grants from the Camilla Samuels Fund and the Imperial Cancer Research Fund, to whom we express our gratitude. We also thank Mrs Doreen Watson, of the Greater Glasgow Health Board, for her help. The Scottish Melanoma Group is funded by grant number K/MRS 50 C363 from the Scottish Home and Health Department.

\section{References}

1 Balch C.M, Milton GW. Cutaneous melanoma. Clinical management and treatment results worldwide Philadelphia: J P Lippincott, 1985

2 MacKie RM, Soutar DS, Watson ACH, et al. Malignant melanoma in Scotland 1979-83. Lancel $1985:$ ii: $859-62$

3 Office of Population Censuses and Survevs. Cancer survival statistics, England and W'ales. London HMSO, 1982. Series MBI, No 9.

4 Breslow A. Thickness, cross sectional area and depth of invasion in the prognosis of cutaneous melanoma. Ann Surg 1970;172:902-8.

5 Breslow A, Macht SD. Evaluation of prognosis in stage 1 cutaneous melanoma. Plast Reconstr Surg 1978:61:342-6.

6 Cox EB, Vollmer RT, Seigler HF. Melanoma in the south east United States: experience at the Duke Medical Center. In: Balch CM, Milton GW, eds. Cutaneous melanoma. Philadelphia: J B Lippincott, 1985:407-19.

7 McCarthy WH, Shaw HM, Milton GW, McGovern VJ. Melanoma in New South Wales Australia experience at the Sydney Melanoma Unit. In: Balch CM, Milton GW, eds. Cutaneous melanomu. Philadelphia: J B Lippincott, 1985:371-9.

8 Eldh J, Boeryd B, Suurkula M, Peterson LE, Holmstrom H. Melanoma in Sweden. In: Balch CM Milton GW, eds. Cutaneous melanoma. Philadelphia: J B Lippincott, 1985:469-77.

9 Temoshok L, DiClemente RF, Sweet DM, Blois MS, Sagebiel RW. Factors relating to patient delay in seeking medical attention for cutaneous malignant me:anoma. Cancer 1984;54:218-23.

Accepled 25 February 1986 